\title{
Research Article \\ Serum Paraoxonase with HDL-C as a predictor of atherosclerosis in patients of Chronic Kidney Disease
}

\author{
Chaganti Sridevi $^{1}$, UVPU Sowjanya ${ }^{2}$, V. S. Kalai Selvi ${ }^{3}$, DMM Rajakumari ${ }^{4}$, Kasi Babu ${ }^{5}$ \\ ${ }^{1}$ Assistant Professor, ${ }^{3}$ Professor, Biochemistry, Sree Balaji Medical College and Hospital, Chrompet Chennai 600044, Tamil \\ Nadu \\ ${ }^{2}$ Assistant Professor, Biochemistry, Maharaja Institute of Medical Sciences, Nellimerla Vizianagaram Andhra Pradesh \\ ${ }^{4,5}$ Professor, Biochemistry, Andhra Medical College, Visakhapatnam, Andhra Pradesh
}

(Received: January $2020 \quad$ Revised: November 2020

Accepted: December 2020)

Corresponding author: UVPU Sowjanya. Email: 1987sowji@gmail.com

\begin{abstract}
Introduction and Aim: CKD (Chronic Kidney Disease) is a problem in health care spread all over the world with adverse consequences. CKD is associated with premature atherosclerosis and increased morbidity and mortality due to cardiovascular complications. Hypertriglyceridemia is a commonly seen lipid abnormality in CKD patients. PON-1 (Paraoxanase-1) is a glycoprotein synthesized in the liver and is released into the blood, where it links with HDL. This study was undertaken to find out the relation between PON-1 and HDL-C and its effect on atherosclerosis.

Materials and Methods: A total number of 123 subjects participated in the study. Serum was used for estimating the parameters such as serum total cholesterol (TC), triglycerides (TG), high-density lipoprotein (HDL), lowdensity lipoprotein (LDL), very low-density lipoprotein (VLDL) by calculation, creatinine, urea in a fully automated analyzer BS300. Serum paraoxonase-1(PON) was estimated by spectrophotometric method.
\end{abstract}

Results: The metabolic derangement was very evident in the CKD group with significantly higher creatinine, urea, and dyslipidemia, and abnormal paraoxonase activity being observed in the cases compared to controls.

Conclusion: This study suggests the need for assessing PON-1 activity, a measure of the antioxidant capacity of HDL-C which improves the predictive accuracy of atherosclerosis in CKD.

Keywords: Chronic kidney disease; paraoxonase; HDL-C; atherosclerosis, dyslipidemia; hemodialysis

\section{INTRODUCTION}

O KD (Chronic Kidney Disease) is a problem in health care spread all over the world with adverse consequences. Kidney Disease Quality Outcome Initiative (K/DOQI) developed a simple definition and classification system. The K/DOQI definition and classification are accepted with clarifications. The definition (1) of CKD is the damage of the kidney or GFR $<60 \mathrm{ml} / \mathrm{min} / 1.73 \mathrm{~m}^{2}$ for 3 months or more irrespective of the cause. Serum urea and creatinine, and many toxins that accumulate in renal failure have been associated with the uremic syndrome. Hypertriglyceridemia is a commonly seen lipid abnormality in CKD patients. The increased concentration of triglycerides in pre-dialysis (2) patients is owing to tardy catabolism. CKD patients, irrespective of the presence of heavy proteinuria, show important qualitative variations in LDL metabolism (3). The quantity of highly atherogenic small dense LDL particles is increased. Thus, CKD is associated with premature atherosclerosis and increased morbidity and mortality due to cardiovascular complications.

PON-1 (paraoxonase-1) is a glycoprotein synthesized in the liver and is released into the blood, where it links with HDL (4). It is located on human chromosome 7 and is a member of a three-gene family consisting of PON-1, PON-2, and PON-3. It is an efficient esterase towards many organophosphate compounds including paraoxon and also hydrolyses aliphatic lactones such as dihydrocoumarin, homocysteine thiolactone, etc. PON is seen in plasma, bound tightly with the high-density lipoprotein complex. PON-1 can inhibit LDL lipid peroxidation and can inactivate LDL-derived oxidized phospholipids (5). This could reduce the serum content of oxidized lipids involved at the beginning of atherosclerosis. The activity and concentration of PON-1 vastly fluctuate in different populations. The enzyme characteristics in serum are likely to be important for an individual's response to the risk of evolving vascular disease. It was found that treatment of oxidized LDL with purified PON1 considerably reduced the capacity of this lipoprotein to induce monocyte endothelial interactions and that this effect was associated with a decrease in oxidized phospholipid component in LDL particle (particularly of oxidized 1 - palmitoyl-2- arachidonoyl- glycero 3 - phosphoryl-choline).

It was suggested that the physiologic function of PON1 might be to defend the inflammatory response generation in the arterial wall by terminating biologically active phospholipids in oxidized LDL (6). A further study showed that PON1 not only 
protects LDL molecule from lipid peroxidation but HDL molecule as well. PON-1 level can be altered by acquired factors like lifestyle, diet, and disease. PON activity has also been found to be increased with higher intakes of vitamin $E$ and vitamin $C$ (7). Ethanol usually inhibits serum PON activity. Smoking and tobacco usage are also associated with decreased PON activity. HDL is the serum carrier for PON-1 and it is likely to be the chief factor for enzyme concentration as the PON-1 levels are decreased in HDL deficiency syndromes.

This study was done to correlate HDL concentration and PON-1 activity in CKD patients admitted in a tertiary care government hospital.

\section{MATERIALS AND METHODS}

A cross-sectional study of serum lipid profile, serum creatinine, blood urea, and PON-1 activity in patients with CRF undergoing medical treatment or hemodialysis was done. Clinically diagnosed cases of CKD admitted in the nephrology department of King George Hospital attached to Andhra Medical College, Visakhapatnam were selected. Healthy controls were selected from regular blood donors in the blood bank, King George Hospital. Informed written consent was taken from each subject. The cases and controls willingly participated in the study.

A total number of 123 subjects participated in the study. Group1 constituted of 41 subjects who were CKD patients on medical treatment, Group 2 consisted of 40 subjects who were CKD patients on hemodialysis, and Group 3 consisted of age and sexmatched 42 subjects who were healthy controls.

\section{Inclusion criteria}

Clinically diagnosed cases of CKD between 20-60 years age group on medical treatment or hemodialysis.

\section{Exclusion criteria}

Patients with

1. Liver diseases, alcohol abuse

2. Infectious diseases

3. Familial hyperlipoproteinemia, lipid profile altering diseases

4. Malignancies

5. Using Hypolipidemic drugs, using any multivitamins including vitamin $\mathrm{C}$ and vitamin $\mathrm{E}$ supplements

\section{Sample collection}

Under aseptic precautions, about $5 \mathrm{ml}$ of blood was collected in a sterile vacutainer from selected CKD patients on medical treatment and hemodialysis. Serum was separated after centrifugation and was used for the analysis of the following parameters. No special dietary instructions were given before collecting the blood samples.

\section{Parameters}

Serum was used for estimating the following parameters serum total cholesterol (TC), triglycerides (TG), high-density lipoprotein (HDL), low-density lipoprotein (LDL), very low-density lipoprotein (VLDL) by calculation, urea (8), creatinine (9) in a fully automated analyzer BS300. Serum Paraoxonase-1(PON) was estimated by spectrophotometric method $(10,11)$. Paraoxonase activity was estimated spectrophotometrically using an assay mixture consisting of $5.5 \mathrm{mM}$ 4-nitrophenyl acetate as the substrate in $20 \mathrm{mM}$ Tris-HCL buffer containing $1 \mathrm{mM} \mathrm{CaCl} 2$ at $\mathrm{pH}$ of 8.0 and $50 \mu \mathrm{l}$ of fresh serum sample. For salt stimulated $\mathrm{PON} 1 \mathrm{mM} \mathrm{NaCl}$ is also used. The intensification in absorbance due to the formation of the yellow-colored 4-nitrophenol was observed at a wavelength of $412 \mathrm{~nm}$ for 3 minutes. PON1 was taken as $1 \mathrm{U} / \mathrm{ml}$ when the rate of formation of the product 4-nitrophenol was 1nano $\mathrm{mol} / \mathrm{ml}$ of the serum under the assay conditions (7). 4-nitrophenyl acetate was procured from Sigma Aldrich Chemicals. Analytical grade chemicals were used for the assay of PON1 activity. For all samples, the activity of basal PON and activity of salt stimulated PON was estimated.

\section{Statistical methods}

The statistical analysis was carried out by using the SPSS (Statistical package for social sciences) software. Independent sample ' $t$ ' test was used to compare mean values. Pearson's correlation coefficient analysis was used to find out the degree of correlation between parameters. The level of statistical significance set at $\mathrm{p}<0.001$ was considered highly significant.

\section{RESULTS AND OBSERVATIONS}

A comparative study with 81 clinically diagnosed CKD patients and 42 controls was undertaken. The cases were evaluated clinically and segregated into two groups. Group 1 comprised 41 patients who were on medical treatment and another 40 patients on hemodialysis were in group 2. All patients were classified based on clinical picture as well as biochemical investigations. The metabolic derangement was very evident in the CKD group with significantly higher creatinine, urea, and dyslipidemia, and abnormal paraoxonase activity being observed in the cases compared to controls. This difference was even more obvious in group 2 patients comprising of hemodialysis cases in comparison to group 1 patients on conservative medical management.

Table 1: Age distribution in CKD cases and controls

\begin{tabular}{|l|l|l|}
\hline Age (years) & Cases $(\mathrm{n}=81)$ & Controls $(\mathrm{n}=42)$ \\
\hline $21-30$ & 9 & 5 \\
\hline $31-40$ & 16 & 25 \\
\hline $41-50$ & 23 & 10 \\
\hline
\end{tabular}




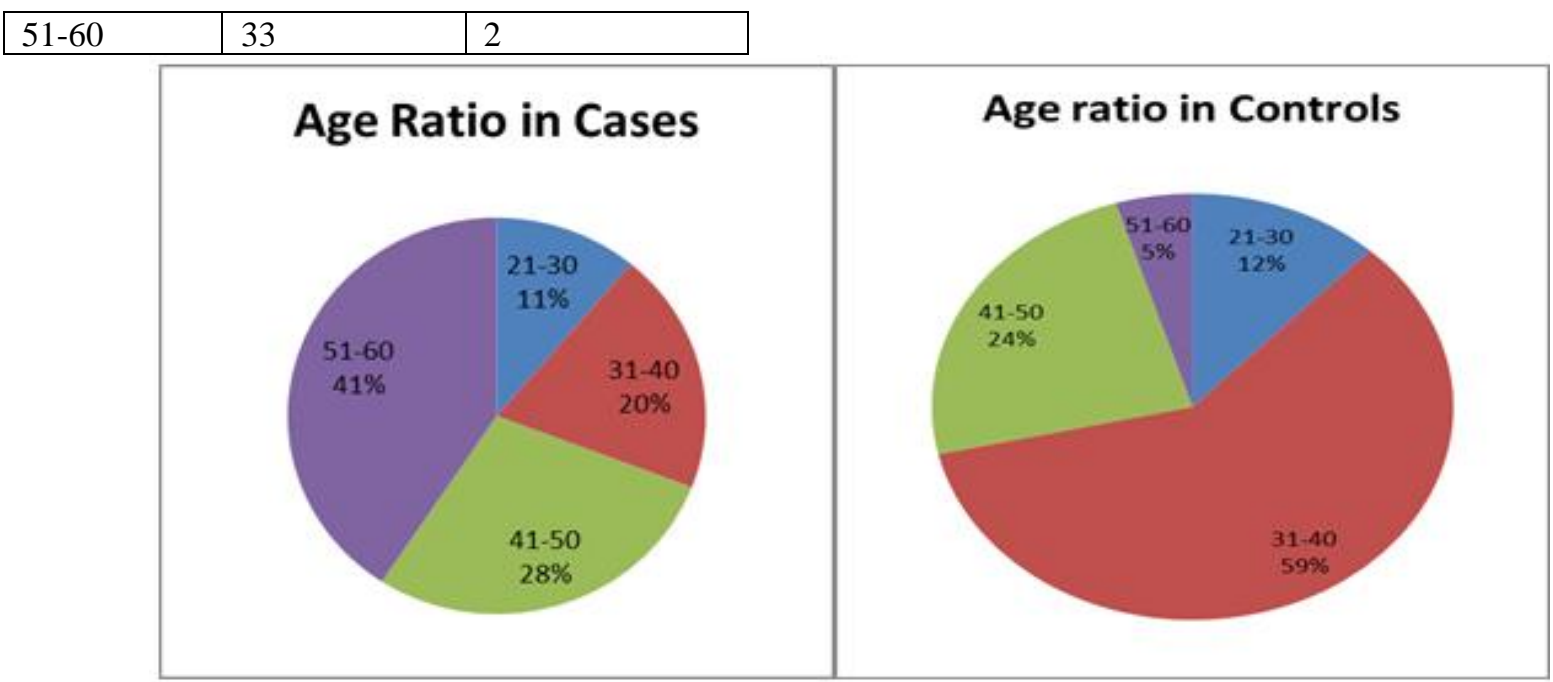

Fig. 1: Age ratio in CKD cases and controls

In the present study as seen in table 1 and figure 1, the age group of 51-60 years comprised the majority of cases i.e. $41 \%$.

Table 2: The concentrations of all parameters in controls (group 3), patients with CRF (group 1) and patients undergoing dialysis (group 2)

\begin{tabular}{|c|c|c|c|c|c|}
\hline Parameters & $\begin{array}{c}\text { CKD on medical } \\
\text { treatment (Mean } \\
\mathbf{\pm} \text { SD) } \\
\text { Group1 (n=41) }\end{array}$ & $\begin{array}{c}\text { p- } \\
\text { value }\end{array}$ & $\begin{array}{c}\text { CKD on } \\
\text { Hemodialysis } \\
\text { (Mean } \pm \text { SD) } \\
\text { Group 2 (n= 40) }\end{array}$ & p-value & $\begin{array}{c}\text { Controls (Mean } \\
\mathbf{\pm} \text { SD) } \\
\text { Group 3 (n=42) }\end{array}$ \\
\hline Blood urea (mg/dL) & $120.58 \pm 14.18$ & 0.001 & $98.5 \pm 39.2$ & 0.001 & $27 \pm 7.07$ \\
\hline Creatinine(mg/dL) & $4.57 \pm 0.72$ & 0.001 & $4.37 \pm 0.49$ & 0.001 & $1.17 \pm 0.3$ \\
\hline Total Cholesterol(mg/dl) & $209.6 \pm 17.8$ & 0.01 & $204.28 \pm 17.13$ & 0.01 & $174.48 \pm 15.9$ \\
\hline HDL-Cholesterol(mg/dl) & $34.28 \pm 7.4$ & 0.001 & $37.25 \pm 9.9$ & 0.001 & $42.35 \pm 4.07$ \\
\hline Basal PON(U/L) & $160.1 \pm 9.4$ & 0.0001 & $188.35 \pm 65.75$ & 0.0001 & $383 \pm 41.5$ \\
\hline Salt stimulated PON(U/L) & $205.73 \pm 24.5$ & 0.0001 & $282.15 \pm 74.54$ & 0.0001 & $536.9 \pm 84.2$ \\
\hline
\end{tabular}

*p-value $<0.001$ is considered statistically significant

As seen in table 2 there was a significant rise of blood urea and serum creatinine in cases (both group 1 and group 2) when compared to controls. Total cholesterol also showed a significant elevation in cases when compared to controls. HDL-C is decreased in cases in comparison with controls. PON-1 (basal and salt stimulated) was decreased in cases compared to controls.

Table 3: Karl Pearson's coefficient of correlation (r-value) of PON-1 with HDL, blood urea, serum creatinine in controls (group 3), cases with CKD (Group 1), and cases with CKD undergoing hemodialysis (Group 2).

\begin{tabular}{|c|c|c|c|}
\hline Parameter & $\begin{array}{c}\text { Group } \\
\text { 1(CKD) }\end{array}$ & $\begin{array}{c}\text { Group } \\
\text { 2(CKD } \\
\text { on HD) }\end{array}$ & $\begin{array}{c}\text { Group } \\
\text { 3(controls) }\end{array}$ \\
\hline $\begin{array}{c}\text { PON vs } \\
\text { Creatinine }\end{array}$ & -0.322 & -0.243 & -0.731 \\
\hline $\begin{array}{c}\text { PON vs } \\
\text { Blood urea }\end{array}$ & -0.669 & -0.592 & -0.603 \\
\hline $\begin{array}{c}\text { PON vs } \\
\text { HDL-C }\end{array}$ & +0.878 & +0.624 & +0.738 \\
\hline
\end{tabular}

There was a negative correlation between PON-1 and creatinine, PON-1 and urea in cases. There was a positive correlation between PON-1 and HDL-C in cases. This is well evident from table 3.

\section{DISCUSSION}

Chronic renal failure is the leading cause of increased sickness and death in the general population. CKD is described as a gradual reduction in the number and function of the nephron. There is a reduction in the concentrating ability of the kidney leading to the amassing of urea and creatinine in the blood. CKD is associated with hypercholesterolemia which is caused due to related renal insufficiency and proteinuria. Patients with CKD usually present with a clinical picture of early atherosclerosis. The significant mechanisms of atherogenesis in CKD are disorders of lipoprotein metabolism, imbalance between the 
generation of free radicals and antioxidant defense system, and PON-1 activity during uremia and dialysis.

In the present study blood urea and serum creatinine were significantly elevated in patients with CKD when compared to controls as shown in table 2. Our results were similar to those obtained by Pandya. D et.al., (12). Renal insufficiency combined with heavy proteinuria leads to acquired LDL receptor insufficiency which plays a crucial role in the origin of the accompanying hypercholesterolemia in CKD. In the present, study serum cholesterol levels were elevated in CKD patients when compared to controls as shown in table 2. Muh Geot Wong et al., (13) study also showed similar findings. In the present study, HDL-C was found to be reduced in CKD patients when compared to controls as in table 2. This was similar to the findings of Kawachi.et.al., (14) study. Our present study showed that PON-1 activity (both basal and salt stimulated PON -1) was reduced in CKD patients who were on medical treatment when compared to the controls as shown in table 2. PON-1 activity was reduced in CKD patients who were on hemodialysis when compared to controls. The present study, reduction in basal and salt stimulated Serum Paraoxonase activities, agrees with the study of Dantoine et al., (16). In this study, Dantoine et al., described the decreased activity of Paraoxonase in CKD patients receiving regular hemodialysis (HD) treatment and also those on conservative treatment when compared to controls and, the reduction was more distinct in group 2 (hemodialysis). Dirican et al.,(15) also stated that in uremic pre dialysis and hemodialysis patients lower serum Paraoxonase activity was observed. A similar observation of reduced PON-1 activity in CKD patients was seen in studies done by Schiavon et al., (11).

Impaired clearance of VLDL and chylomicronsis seen in relation to CKD. This is due to dysregulation of hepatic lipase, LPL (lipoprotein lipase), VLDL receptor, hepatic LCAT, and LRP (LDL receptorrelated protein) expression/activities and impaired HDL metabolism leading to an increased level of VLDL-C (19-21). A reduced level of HDL leads to a decrease in its ability to protect against LDL oxidation. Thus, lipid abnormality including hypertriglyceridemia, presence of small dense LDL, and susceptibility to oxidation add synergistically to atherogenic profile in hemodialysis patients. Oxidative stress is responsible for the oxidative alteration of LDL. This modified LDL is known to accelerate the process of atherosclerosis more than the native LDL. In CKD patients, the vulnerability of LDL to oxidative change is very high signifying that the protection of lipoproteins against oxidation might be impaired. PON-1 possesses peroxidase-like activity that can contribute to its protective effect against lipoprotein oxidation considering the suspected defensive part of Paraoxonase in atherosclerosis. It is noted that aging also causes a reduction in enzyme activity.

In CKD patients, the result of increased oxidative stress on LDL lipoproteins in vitro has been reported and it has been noticed in patients with familial hypercholesterolemia, diabetes mellitus, or coronary heart disease. The present study showed the relationship between reduced Paraoxonase activity, lower antioxidant defense, and increased lipid peroxidation (17). Paraoxonase may play its defensive role in atherogenesis by lipid peroxidation products hydrolysis and consequently by LDL oxidation and foam cell synthesis restriction. It has been suggested that the enhanced tendency to atherosclerosis in CKD is contributed by higher oxidative stress and insufficient enzyme activities $(22,23)$.

Loss of protection during uremia represents an important factor in atherosclerosis. The reduction in the activity of PON-1 observed in this study may be the consequence of lower concentrations of HDL-C in CKD because HDL is the leading carrier of PON1. PON-1 inhibits the oxidative modifications of LDL during oxidation in vitro, possibly by destroying active phospholipids in minimally oxidized LDL. Serum PON-1 activity is related inversely to the threat of evolving atherosclerotic lesions. Hemodialysis seemed to be also effective in increasing the serum PON-1 activity of the patients.

Few studies by Jakubowski et al., (25-27) described the substrates and role of Paraoxonase biologically. Their study showed that Paraoxonase is helpful in the hydrolysis of homocysteine thiolactone. It is converted into homocysteine (homocysteine thiolactonase activity). Homocysteine thiolactone is not stable. Binding to proteins at lysine residues gives stability to homocysteine thiolactone. Protein structure is altered by N-homocysteinylation and this augments the exposure to proteolysis. Nhomocysteinylation of Paraoxonase decreases its activity. Thus, a fall in activity of Paraoxonase may start a positive feedback mechanism because the reduced activity of Paraoxonase is the basis of further increase of homocysteine thiolactone and it enhances protein homocysteinylation.

This study also showed a negative correlation with blood urea, serum creatinine, and a positive correlation with HDL-C as shown in table 3. Studies by Dirican et al., (15) also showed similar findings. Reduction in HDL concentration and PON-1 activity causes an increased risk of atherogenesis in patients with CKD.

\section{CONCLUSION}

Central role in the genesis of the associated hypercholesterolemia in CKD is played by acquired 
LDL receptor deficiency due to renal insufficiency or in combination with heavy proteinuria. CKD patients undergoing hemodialysis show increased generation of reactive oxygen species accompanied by altered lipid profile and PON-1activity. This study suggests the need for assessing PON-1 activity, a measure of the antioxidant capacity of HDL-C which improves the predictive accuracy of atherosclerosis in CKD and this antioxidant capacity can be enhanced by initiating the antioxidant therapy in patients undergoing hemodialysis for CKD.

\section{CONFLICT OF INTEREST}

Conflict of interest declared none.

\section{REFERENCES}

1. Bargman, J. M., Skorecki, K. Chronic Kidney Diseases. In: Fauci Braunwald, Kasper, Hauser, Longo, Jameson, et al, editors. Harrison's Principles of internal medicine vol 2. 17th Ed. New York: McGraw Hill; 2008. p. 1761-1762.

2. Gupta, K., Mahajan, R. Coronary risk factors in maintenance hemodialysis patients: who is the culprit hemodialysis or chronic renal failure? Int J App Basic Med Res 2011;(1):11-14.

3. Mekki, K., Prost, J., Remaoun, M., Belleville, J., Bouchenak, M. Long term hemodialysis aggravates lipolytic activity reduction, and very low density, low-density lipoproteins composition in chronic renal failure patients. BMC Cardiovascular disorder 2009; 9:41.

4. Marsillach, J., Aragones, G., Mackness, B., Mackness, M., Rull, A., Beltran -Debon, R et al., Decreased paraoxonase-1 activity is associated with alterations of HDL particles in chronic liver impairment. J Lipid Health Dis 2010; 9:46.

5. Daschner, M., Lenhartz, H., Botticher, D., Schaefer, F., Wollschlager, M., Mehls, O., et al., Influence of Dialysis on Plasma Lipid Peroxidation products and antioxidant levels. Kidney Int1996; (50):1268-1272.

6. Nagane, N. S., Ganu, J. V. Lipid Profile and Serum Paraoxonase 1 activity in CRF patients pre \& post hemodialysis. Al Ameen J Med Sci 2011;4(1): 61-68.

7. Dillard., Kunert, K. J., Tappel. Effects of vitamin E, Ascorbic acid, and Mannitol on Alloxan induced lipid peroxidation in rats. Arch Biochem Biophysics 1982; 216(1): 204-212.

8. Kaplan, A. Urea. In: Amedeo JP, Lawrence AK, editors. Methods in clinical chemistry 1st ed: St Louis: C.V. Mosby company; 1987: 22-26.

9. Robert, L. M. Creatinine. In: Amedeo, J. P., Lawrence, A. K., editors. Methods in clinical chemistry 1st ed: St. Louis: C.V. Mosby company;1987: $10-17$.

10. Paragh, G., Asztalo, S. L., Seres, I. Serum Paraoxonase activity changes in uremic and kidney transplanted patients. Nephron 1999; 83(2): 126-131.

11. Schiavon, R., De Fanti, E., Giavarina, D., Biasioli, S., Cavalcanti, G., Guidi, G. Serum paraoxonase activity is decreased in uremic patients. Clin Chim Act 1996; 247:7180.

12. Pandya, D., Nagrajappa, A. K., Ravi, K. S. Assessment and Correlation of Urea and Creatinine Levels in Saliva and Serum of Patients with Chronic Kidney Disease, Diabetes and Hypertension- A Research Study. Journal of clinical and diagnostic research: JCDR, 2016; 10(10): ZC58-ZC62.

13. Wong, M. G., Wanner, C., Knight, J., Perkovic, V. Lowering cholesterol in chronic kidney disease: is it safe and effective? European Heart Journal. 2015; 36(43); 29882995. https://doi.org/10.1093/eurheartj/ehv393

14. Kawachi, K., Kataoka, H., Manabe, S., Mochizuki, T., Nitta, $\mathrm{K}$. Low HDL cholesterol as a predictor of chronic kidney disease progression: a cross-classification approach and matched cohort analysis. Heart Vessels. 2019 Sep;34(9):1440-1455. doi: 10.1007/s00380-019-01375-4. Epub 2019 Mar 14. PMID: 30874893.

15. Dirican, M., Akca, R., Sarandol, E. Serum Paraoxonase activity in uremic predialysis and hemodialysis patients. J Nephrol 2004; 17 (6): 813 -818.

16. Dantoine, T. F., Debord, J., Charmes, J. P., Merle, L., Marquet, P., Lachatre, G., et al., Decrease of Serum Paraoxonase activity in chronic renal failure. J Am Soc Nephrol 1998; 9: 2082-2088.

17. Sumathi, M. E., Tembad, M., Murthy, J., Preethi, B. P. Study of Lipid Profile and Oxidative Stress in CRF. Biomed Res 2010; 21(4): 451-456.

18. Prakash, M., Shetty, J. K., Rao, L., Sharma, S., Rodrigues, A., Prabhu, R., et al., Serum paraoxonase activity and protein thiols in chronic renal failure patients. Indian $\mathbf{J}$ of Nephrol 2008; 18(1): 13-16.

19. Rifa, N., Warnick, G. R. Lipid, Lipoproteins, Apolipoproteins, and other cardiovascular risk factors. In: Brutis, CA., Ashwood, ER., Bruns, De. Editors Teitz textbook of clinical biochemistry and molecular diagnostic. $4^{\text {th }}$ ed. New Delhi: Elsevier's;2006 p:942-960.

20. Sarkar, P. D., Shivaprakash, T. M., Madhusudan, B. Association between paraoxonase activity and lipid levels in patients with premature coronary artery disease. Clinica Chimica Acta 2006; 373: 77-81.

21. Rosenblat, M., Volkova, N., Ward, J. Paraoxonase 1 (PON1) inhibits monocyte to macrophage differentiation. Atherosclerosis 2011; 219 (1): 49-56.

22. Saeed, S. A., Elsharkawy, M., Elsaeed, K. Paraoxonase 1 (PON1) activity as a risk factor for atherosclerosis in chronic renal failure patients. Hemodial Int 2008; 12(4) : 471-479.

23. Daniel, E. W., Hocine, T., Manish, G. A. Chronic Kidney Disease as a Risk Factor for Cardiovascular Disease and All-Cause Mortality; A PooledAnalysis of Community Based Studies. J Am Soc Nephrol 2004; 15: 1307-1315.

24. Foley, R. N., Parfrey, P. S., Sarnak, M. J. Clinical epidemiology of cardiovascular disease in chronic renal failure. Am J Kidney Dis 1998; 32(5): S112-119.

25. Perła-Kaján, J., Jakubowski, H., Hieronim. Paraoxonase 1 and homocysteine metabolism. Amino acids. 2012; 43: 1405-1417.

26. Jakubowski, H., Ambrosius, W. T., Pratt, J. H. Genetic determinants of homocysteine thiolactonase activity in humans: implications for atherosclerosis. FEBS Lett, 2001; 491: 35-39.

27. Jakubowski, H., Zhang, L., Bardeguez, A., Aviv, A. Homocysteine thiolactone and protein homocysteinylation in human endothelial cells: implications for atherosclerosis. Circ Res, 2000; 87: 45-51. 